J. Andersen (ed.), Reports on Astronomy, Vol. XXIVA, 423-425.

(C)2000 IAU. Printed in the United States of America.

\title{
COMMISSION 46: TEACHING OF ASTRONOMY
} (ENSEIGNEMENT DE L'ASTRONOMIE)

\section{PRESIDENT: Julieta Fierro}

VICE-PRESIDENT: Syuzo Isobe

ORGANIZING COMMITTEE: B. Jones, A. Batten, A. Arellano, M. Gervaldi, E. Guinan, W. Tush, D. Hoff, P. Martínez, D.McNally, A. Norton, J. Narlikar, J. Pasachoff, J. Percy \& D. Wentzel

\section{INTRODUCTION}

Commission 46 is dedicated to Teaching of Astronomy. Commission 46 can be seen as an extension of the IAU Executive Committee in the sense that each adhering country has appointed a national representative to the Commission. National Representatives maintain liaison between the Commission and the home country, and write national triennial reports on development of astronomy on their nations. Other IAU astronomers, with special interest in education, can become regular individual members of the Commission. Non-IAU members can be invited by the Commission to serve for one triennial term. Commission 46 considers that one of its major duties is to contribute to enhance astronomy education in developing countries. The Newsletter, the International School for Young Astronomers, the Visiting Lecturer Program and the Travelling Telescope are examples of such activities administered by the Commission. The strength of Commission 46 comes from the hard work that its members do in order to promote astronomy education worldwide.

\section{SPECIAL PROJECTS}

\subsection{International Schools for Young Astronomers (ISYA)}

These three-week schools aimed at graduate students and other young astronomers in some region of the developing world. They include lectures and practical work, and are intended to expose the young astronomers to a series of research topics chosen by the organizers. The schools also provide the young astronomers with an international perspective, and with contacts with other young astronomers in their region as well as with the lecturers at the school. The 23rd ISYA met July $4-23,1997$ in the mile-high city of Zanjan, Iran, on the attractive campus of the Institute for Advanced Studies in Basic Sciences (IASBS), at the invitation of its Director, Dr. Y. Sobouti. In 1999 an ISYA was held in Romania. Contact person: Michele Gerbaldi (gerbaldi@iap.fr). Reports can also be found at: http://www.iau.org.

\subsection{Teaching For Astronomical Development (TAD)}

This program is designed to assist in astronomy development in specific countries. It has operated in Paraguay, Peru and Vietnam. Contact people are: Derek McNally (dmn@star.ucl.ac.uk) and Donat Wentzel (wentzel@astro.umd.edu). During the present term, a Summer School on Astrophysics was held at Vinh University, Vietnam, August 31 to September 12, 1997. This conference is central to the TAD program to re-introduce astronomy to Vietnam. It was organized by Prof. Nguyen Dinh Huan, vice-rector of Vinh University. Development of astronomy in six countries of Central America is being carried out, in part, through the IAU Teaching for Astronomical Development program. The V 
CURCAA, V Curso Centro Americano de Astronomia y Astrofísica (Fifth Central American Workshop on Astronomy and Astrophysics) was held in Managua, Nicaragua in June 1999. Contact person Armando Arellano (arellano@astroscu.unam.mx)

\subsection{The Travelling Telescope (TT)}

Commission 46 owns a Celestron- 8 telescope, equipped with basic instrumentation for photometry, that is sent to different countries to promote observational astronomy. Its photometer has been used in Central America and now the telescope is being sent to Morocco on long-term loan. The contact person is John Percy (jpercy@erin.utoronto.ca)

\subsection{Books and Journals for Developing Countries}

Commission 46 has a sub-committee to transfer surplus books and journals to institutions which have demonstrated need for them, the contact person is Darrel B. Hoff (hoffdarr@martin.luther.edu). It has also promoted the creation of virtual libraries which include main journals, books and teaching projects in local languages.

\subsection{Eclipses}

A sub-committee of Commission 46 deals with ways in which countries can use solar eclipses and other astronomical events to develop local astronomical education. The sub-committee has expertise in astronomy education at many levels, research and safe solar eclipse viewing. The contact person is Jay Pasachoff, jmp@williams.edu. The documents elaborated by the sub-committee were particularly useful during the 1998 and 1999 eclipses.

\subsection{Rocket Challenge}

A recent program of Commission 46 is to promote interest for Astronomy constructing water rockets. The contact person is: John Baruch (J.E.F.Baruch@Bradford.ac.uk) and its website is: http://www.brad.ac.uk/acad/cybernet/rockets/

\section{WORKING GROUPS}

Commission 46 has strong liaisons with other commissions, working groups and organizations with common interests such as Commission 38, dedicated to the Exchange of Astronomers and Commission 50, concerned with the Preservation of Dark Skies. The Working Group is dedicated to the Worldwide Development of Astronomy and will hold a Joint Discussion in Manchester 2000. The contact person is Alan Batten (batten@dao.nrc.ca). The International Planetarium Society plays a very important role in promoting astronomy, its president is William Gutsch (102417.2073@CompuServe.com).

\section{MAJOR SCIENTIFIC CONFERENCES 1997 - 1999}

Commission 46 encourages meetings on education. There were meetings on light pollution in Athens and Vienna. Reports will be published in our Newsletter. A UN/ESA Workshop on Basic Space Science was held in Honduras, and marked the inauguration of the astronomical observatory there. In 1998, the total solar eclipse on February 26 brought together two important events in Panama: the IV Central American Teaching of Astronomy for development. In Jordan two United Nations/ESA meeting were held, one a Workshop on Basic Space Science with IAU participation. There is now an astronomy magazine edited in Arab language. The UN Office for Outer Space Affairs contact person is Hans J. Haubold (haubold@vs.kph.tuwien.ac.at). A meeting on education was held in the UK organized by B. Jones and D. McNally, sponsored by the Royal Astronomical Society. The Australian and New Zealand Astronomical Societies cosponsored an meeting on teaching of astronomy in Australia organized by Graeme White, July 1999. The proceedings will be published in the 
Publications of the Astronomical Society of Australia (PASA). The International Council of Scientific Unions held a conference on Capacity of Building Science that dealt, amongst other things, on innovative ways to teach science, in particular for girls. The presentations were published electronically and can be found at: http://www.teachscience.org

Unispace III Conference was held in Vienna, its purpose was to enhance the peaceful uses of space. An IAAU/COSPAR UN Educational Workshop on teaching of astronomy was held as part of the workshops that would lead to a series of recommendations to the assembly. The proceedings of the astronomy workshop will be published in Asian Pacific Teaching of Astronomy, edited by Syuzo Isobe.

\subsection{Teacher workshops}

Commission 46 promotes teacher training by encouraging the creation of a wide variety of educational materials. It also organizes teacher workshops at the same time as the IAU General Assembly and other meetings. In Tokyo it was organized by Syuzo Isobe (isobesz@cc.nao.ac.jp) During the Astronomical Meeting of the Astronomical Societies of Australia and New Zealand, a Teacher's Workshop was held at the Sydney Observatory in July 1999.

\section{MAJOR PUBLICATIONS 1997 - 1999}

The IAU Colloquium, 162, New Trends in Astronomy Teaching was held in London UK in July 1996. The Proceedings are now available, published by Cambridge University Press, 1998, Edited by L. Gouguenheim, D. McNally, and J. Percy. Part of it is available in electronic form: dmn@star.ucl.ac.uk. The proceedings include topics ranging from public, school and university education in astronomy, to distance learning and electronic media and the increasing role it could play in on campus teaching, as well as the use of the internet in all forms of astronomy teaching.

\subsection{Newsletter and webpage}

Commission 46 runs a quarterly Newsletter that serves as a link between astronomers interested in astronomy education. Its editor is Barrie Jones. It is available in electronic format: http://physics.open.ac.uk/IAU46/newsletter49.html. It includes among other items national triennial reports on the status of astronomy education in every nation that is member of the International Astronomical Union. It also reports on meetings on education and includes a wide variety of educational items.

\section{SOURCES OF FURTHER INFORMATION}

The IAU Commission 46 webpage can be found at http://physics.open.ac.uk/IAU46/, linked from the IAU site http://www.iau.org/; it is maintained by Andy Norton (A.J.Norton@open.ac.uk.) 